\title{
Classical conditioning and extinction of the licking response in rats'
}

\author{
RICHARD L. PATTEN ${ }^{2}$, STATE UNIVERSITY OF IOWA \\ EDWARD B. DEAUX, THE UNIVERSITY OF TEXAS
}

Data from an experimental group and a pseudoconditioning control group show that licking responses in rats can be classically conditioned and that this conditioning occurs within 60 trials and extinguishes rapidly when water reinforcement is removed.

The relative paucity of psychological research in the area of classical reward conditioning has been due largely to the difficulties attendant on the use of the salivary response, which requires complex measuring techniques and somewhat difficult operative procedures. Miller (1961) introduced a method used in classical conditioning for recording the licking response in the rat by means of an oral fistula, but again an operation was required and the animal had to be restrained. A simple technique has recently been developed (Deaux \& Patten, 1964) for recording licks from a moving rat, and, as it involves neither operative procedures nor restraint, this method lends itself nicely to classical conditioning.

In our earlier study, this recording technique was used in an instrumental runway situation to measure the anticipatory goal response $\left(r_{g}\right)$ which, according to Sience (1956), is a classical conditioned response evoked by stimulus cues at the beginning of the alley. In order for us to establish this licking measure as an operational reference for the $r_{g}$, it is therefore necessary to show that the measured response can be conditioned in the classical conditioning situation.

Method

The subjects (Ss) were 12 naive female hooded rats, approximately 120 days old, 9 of which were assigned to an experimental (conditioning) group and 3 to a control group. All Ss were deprived of water for $22 \mathrm{hr}$. preceding each session. Brierly, the recording technique consisted of the rat's weartng an elastic harness and a headgear which held a small drinking tube $1 / 8$ in in front of its mouth. An electric circuit through $S$ detected each contact its tongue made with the tube, whether water was being presented or not. The only restraint on the rat was that caused by the harness and the polyethylene tubing through which the water reached the drinking tube.

During all the sessions, $S$ was maintained on a 30 in by 18 in elevated platform, with the wires and polyethylene tubing suspended above it to prevent $\mathrm{S}$ from becoming entangled. The licking was recorded for all Ss during a 3 sec. period preceding the conditioned stimulus (CS) onset and during the first $3 \mathrm{sec}$. of the 5 sec. CS, which consisted of a $500 \mathrm{cps}, 70 \mathrm{db}$ tone and the light from a partially darkened $15 \mathrm{w}$ bulb. For Ss in the experimental group, the $3 \mathrm{sec}$. recording period during CS presentation terminated with the onset of the unconditioned stimulus (UCS), which was the presentation of $.075 \mathrm{ml}$ of water over the last $2 \mathrm{sec}$. of the CS. The control group's responses were recorded only on the CS-alone trials. For each trial the number of licks in the pre-CS period was subtracted from the number of licks in the $3 \mathrm{sec}$. period during the CS to give a score of the discriminated licking to the CS.

A pretraining session of 40 UCS-alone presentations was given to all Ss one day before acquisition. During the 3 days of acquisition training, the experimental group received 40 paired presentations of the CS and UCS per day, with randomized intertrial intervals of 50,60 , and $70 \mathrm{sec}$. with a mean of $60 \mathrm{sec}$. On the first day of extinction this group received $5 \mathrm{CS}-\mathrm{UCS}$ pairings followed by $30 \mathrm{CS}-a$ lone presentations. Fifteen more extinction trials were given the following day to check for spontaneous recovery; intertrial intervals were the same for extinction and acquisition sessions. The control Ss received 80 random presentations of the CS and the UCS (40 of each) per day with intertrial intervals of 25,30 , and $35 \mathrm{sec}$. with a mean of $30 \mathrm{sec}$. Since, with the difference measure employed, each $\mathrm{S}$ in the experimental group acted as its own control, it was felt sufficient to give the pseudoconditioning control Ss only the random CS and UCS presentations without following this with the CS-alone "extinction trials.

\section{Results and Discussion}

Figure 1 presents the mean difference licking score for each $S$ per trial plotted in blocks of 10 trials in

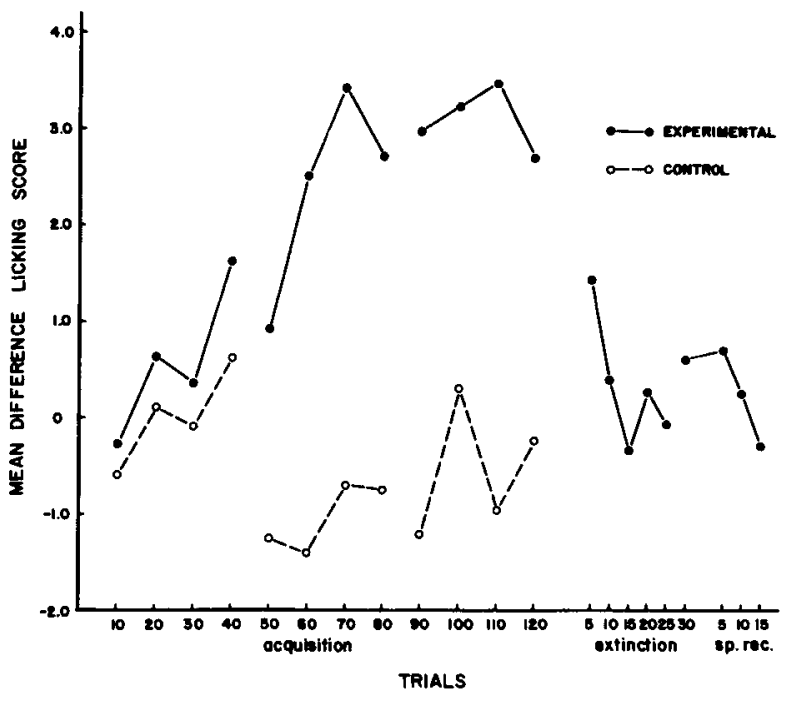

Fig. 1. Mean difference licking scores per trial for subjects in experimental and control groups over acquisition, extinction, and spontaneous recovery sessions. 
acquisition and blocks of 5 trials in the extinction and spontaneous recovery sessions. It can be seen that for the experimental group the differential licking increases until the third day, where it levels off at a difference of about 3.2 responses, which was found to be statistically significant, $t=10.6 ; p<.001$. On day 3 of acquisition, the mean number of responses per trial per experimental $S$ was 2.2 during the pre-CS period and 5.4 during the CS-UCS interval. It is clear that classical conditioning of the licking response did occur and that an apparent asymptote was reached after approximately 70 trials. The control Ss do not show this increased licking to the $\mathrm{CS}$ but rather have a negative mean difference score of licking on days 2 and 3, indicating that there was some inhibition of responding during the $\mathrm{CS}$.

The data from the extinction sessions show that extinction was rapid with practically no acticipatory licking occurring after 15 CS-alone trials. During the first extinction session the mean number of responses per trial per $S$ was 1.3 during the pre-CS period and 1.7 during the CS-UCS interval. The second day's data show very little spontaneous recovery, with less than one response per trial per $S$ in each $3 \mathrm{sec}$. recording period. The rapidity of extinction differs from the findings of previous subhuman classical conditioning studies as does the absence of spontaneous recovery. References

Deaux, E. B., \& Patten, R. L. Measurement of the anticipatory goal response in instrumental runway conditioning. Psychon. Sci., $1964,1,357-358$.

Miller, N. Analytical studies of drive and reward. Amer. Psychologist, 1961, 16, 739-754.

Spence, K. Behavior theory and conditioning. New Haven: Yale University Press, 1956.

\section{Notes}

1. This research was supported in part by an N.S.F. fellowship to the first author. We thank Dr. Kenneth W. Spence for his critical reading of the paper and Gerald Weiss for his assistance in preliminary work.

2. Now at the University of Richmond. 